\section{INFORMÁTICA NA EDUCAÇÃO}

\section{teoria \& prática}

\section{Vol. 24 | N’3 3 | 2021}

ISSN digital ISSN impresso

1982-1654 1516-084X

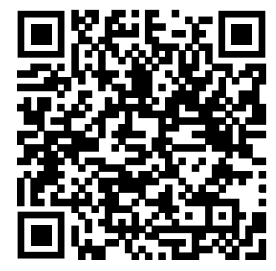

Páginas 102-120

Marize Lyra Silva Passos

Instituto Federal do Espírito Santo marize@ifes.edu.br

Mariella Berger Andrade Instituto Federal do Espírito Santo mariella.andrade@ifes.edu.br

Esther Ortlieb Faria de Almeida Instituto Federal do Espírito Santo esther.ortlieb@ifes.edu.br

\section{UFRGS TDPPGIE}

\section{PORTO ALEGRE}

\section{RIO GRANDE DO SUL}

BRASIL

Recebido em: junho de 2021

Aprovado em: novembro de 2021

\section{Desafio das Metodologias Ativas: construção de um jogo de Escape Room}

\author{
The active Methodologies Challenge: building an \\ Escape Room game
}

Resumo: Este artigo tem como foco descrever o processo de planejamento, implementação e avaliação de um jogo on-line do tipo Escape Room para o ensino de conceitos básicos de metodologias ativas de aprendizagem, para alunos de um curso Técnico Subsequente em Multimeios Didáticos, ofertado na modalidade a distância. Este jogo foi planejado e desenvolvido com base no modelo ADDIE. Para termos uma visão mais holística do jogo, este foi avaliado por alunos do curso citado anteriormente. Os resultados desta avaliação indicaram que, sob o ponto de vista da motivação para a aprendizagem, experiência do usuário e conhecimentos apreendidos, o jogo foi bem avaliado. Este jogo já foi usado em contexto real, no segundo semestre de 2020, junto aos alunos do curso técnico para o qual ele foi planejado.

Palavras-chave: Escape Room. Jogos educativos. Metodologias Ativas de Aprendizagem.

Abstract: This article describes the process of planning, implementing, and evaluating an online game of the Escape Room type for teaching basic concepts of active learning methodologies for students of a Subsequent Technical course in Didactic Multimedia, offered at distance mode. This game was planned and developed based on the ADDIE model. In order to have a more holistic view of the game, it was evaluated by students. The results indicated that, from the perspective of motivation for learning, user experience, and knowledge learned, the game was well evaluated. It was already used in an authentic context with students of the technical courses for which it was planned.

Keywords: Escape Room. Educational games. Active Learning Methodology. 


\section{Introdução}

O termo latino ludus significa diversão e brincadeira e deu origem à palavra jogo. $O$ ato de jogar é uma atividade cultural muito antiga e ultrapassa os limites fisiológicos e psicológicos desse fenômeno, ou seja, como bem destacou Huizinga "[...] todo jogo significa alguma coisa" (HUIZINGA, 2017, p. 4) e tem uma função significante que confere um sentido à ação. Ainda de acordo ele, o ato de jogar não é exclusivo dos seres humanos sendo registrado, também, entre os animais, e, ao ultrapassar "[...] a esfera da vida humana, é impossível que tenha seu fundamento em qualquer elemento racional, pois nesse caso, limitar-se-ia à humanidade" (HUIZINGA, 2017, p. 6).

Desde tempos mais primitivos, os jogos têm sido considerados pelas sociedades como importantes, existindo "[...] antes da própria cultura, acompanhandoa e marcando-a desde as mais distantes origens até a fase de civilização em que agora nos encontramos", estando presente em toda parte, "[...] como uma qualidade de ação bem determinada e distinta da vida comum" (HUIZINGA, 2017, p. 6). Tal importância se destaca visto que os jogos são capazes de promover um ambiente planejado, motivador, agradável e enriquecido, possibilitando a aprendizagem de conteúdos e habilidades diversas. Por apresentar tais características, e corroborando o que ABT (1987, p. 13) ressalta quando afirma que "[...] jogos são dispositivos de ensino e treinamento efetivos para alunos de qualquer idade e em muitas situações, porque são altamente motivadores e comunicam muito eficientemente conceitos e fatos em muitas áreas", o jogo passou a ser incorporado como recurso didático no processo de ensino-aprendizagem.

Os jogos tradicionais, como os de tabuleiros, têm sido utilizados como uma ferramenta importante no processo de ensino-aprendizagem. Mais recentemente, os jogos eletrônicos passaram a ser vistos como uma possibilidade de apoio ao mesmo processo, principalmente após o advento da web 2.0 que disponibiliza ferramentas interativas, o que torna os jogos digitais, em especial os on-line, mais atrativos.

Segundo Mattar (2010, p. xvi), o jogo "[...] já vem sendo explorado há bastante tempo por diversos autores, como o próprio Huizinga", citado anteriormente. No início do século XXI, Prensky (2013) apresentou o conceito de Aprendizagem Baseada em Games Digitais (Digital Game-Based Learning) e afirmou acreditar que, muito antes de os adolescentes daquela época terem netos, o uso de jogos digitais seria uma realidade no apoio à forma como as pessoas aprendem. O autor não estava errado em suas predições e hoje, realmente, esta é uma realidade que não retrocederá.

Contudo, é importante ressaltar que a aprendizagem baseada em jogos é mais do que simplesmente gamificação de materiais educacionais, tendo em vista que o uso de configurações de jogos deve se integrar ao conteúdo de ensino, assim como melhorar a experiência de aprendizagem e, também, estimular o interesse dos alunos (JABBAR; FELICIA, 2015), para que tal uso vá além da prática somente com fins recreativos e transforme-se em um instrumento educacional.

Este trabalho se propõe a apresentar um jogo do tipo Escape Room, que consiste numa aventura na qual os participantes precisam sair de uma sala onde se encontram fechados, superando um conjunto variado de provas e desafios, para encontrar a chave da porta de saída (JIMÉNEZ, 2020). Entre os vários tipos de Escape Room temos o tipo "breakout", que consiste numa aventura na qual os participantes precisam sair de uma sala onde se encontram fechados, superando um conjunto variado de provas e desafios, para encontrar a chave da porta de saída (JIMÉNEZ, 2020). Este tipo de jogo é apropriado para ser utilizado com fins educativos, pois são dinâmicos e facilmente adaptados às salas de aula. Apresentam uma abordagem lúdica, com base em desafios e testes vinculados ao conteúdo curricular.

O uso deste tipo de jogo nos últimos anos se tornou popular e está se tornando cada vez mais frequente no contexto educativo (WIEMKER; ELUMIR; CLARE, 2015), isso pode ser comprovado em uma rápida pesquisa realizada no mês de outubro de 2020, na base de dados da Scopus dentro do Portal de Periódicos CAPES, que encontrou noventa e três (93) artigos científicos publicados em revistas, que tratavam do uso desse tipo de jogo na educação, sendo que destes, cinco no ano de 2017, 7 no ano de 208, 35 no ano de 2019 e 46 no ano de 2020.

Os jogos do tipo Escape Room, em sua grande maioria, ocorrem em um contexto físico. Entretanto, o atual momento de afastamento social no qual nos encontramos nos levou a repensarmos as atividades por nós realizadas presencialmente e nos motivou a construir o jogo de Escape Room em formato virtual acessível, intitulado "O Desafio das Metodologias Ativas", que será utilizado, inicialmente, com uma turma do curso Técnico Subsequente de Multimeios Didáticos, ofertado em uma instituição pública de ensino na modalidade a distância. Este jogo terá como objetivo pedagógico levar 
os jogadores a refletirem sobre o uso de metodologias ativas de aprendizagem em contexto escolar.

\section{Escape Room e seu Valor Educacional}

Em sua essência, os jogos do tipo Escape Room são um entretenimento relativamente novo no qual pequenos grupos de jogadores trabalham juntos dentro de um limite de tempo para completar uma série de desafios (quebra-cabeças) e vencer (escapar de uma sala). Estas salas, geralmente, são baseadas em um tema e uma narrativa (Whitton, 2018; Wiemker; Elumir; Clare, 2015) e possuem as seguintes características: um desafio a superar; uma solução, que pode estar oculta e uma recompensa por superar o desafio.

O termo Escape Room foi referenciado pela primeira vez pela empresa SCRAP, localizada em Kyoto, Japão, e segundo Ouariachi e Wim (2020) até o ano de 2020 já existem cerca de 5.000 em todo o mundo, abrangendo 75 países. No ano passado, houve um crescente interesse entre educadores, de adaptarem o conceito deste tipo de jogo para atender às necessidades de seus alunos em salas de aula, em ambientes de aprendizagem físicos e online.

Em seu trabalho Ouariachi e Wim (2020) identificaram e relacionaram os seguintes atributos positivos no uso dos jogos de Escape Room educacionais: experiência envolvente; resolução de problemas; pensamento crítico; colaboração e senso de urgência. Os alunos, também, podem projetar seus jogos do tipo Escape Room, neste caso, outro benefício, como a criatividade, pode ser adicionado a lista anterior. Quando comparada a outras estratégias de gamificação um dos principais valores agregados dos Escape Room, talvez seja, o mecanismo de cooperação.
Para Zhang et al. (2018), as teorias de aprendizagem mais relevantes relacionadas ao uso de Escape Room na educação são o behaviorismo, a aprendizagem social e o construtivismo. Para estes autores no behaviorismo o comportamento 'positivo' dos jogadores é reforçado ao fornecer progressão ao longo do jogo e a aprendizagem é fornecida por uma 'mudança nas ações por meio de um processo exploratório' que expõe os indivíduos a estímulos externos até que uma resposta desejada seja recebida. Em relação à aprendizagem social, os autores sugerem que os alunos imitem ou perpetuem 0 comportamento de suas experiências de resolução de desafios bem-sucedidos e assimilação de seus conhecimentos e habilidades anteriores, além disso, a teoria da aprendizagem social acredita que as pessoas aprendem observando outras pessoas. E, por fim, os fatores de construtivismo estão ligados ao fato de que os alunos constroem seu próprio conhecimento com base em experiências em tempo real de avançar por vários desafios na sala de fuga.

\section{O Jogo "O Desafio das Metodologias Ativas"}

Nesta seção, apresentaremos a metodologia adotada na criação do Jogo "O Desafio das Metodologias Ativas" e suas características gerais.

\subsection{Metodologia}

Para o desenvolvimento do jogo foi utilizado o modelo ADDIE, que é baseado em cinco fases, descritas na Figura 1: Análise, Projeto, Desenvolvimento, Implementação e Avaliação. Na figura é apresentado, também, os produtos produzidos em cada uma das etapas. 
Figura 1 - Modelo ADDIE

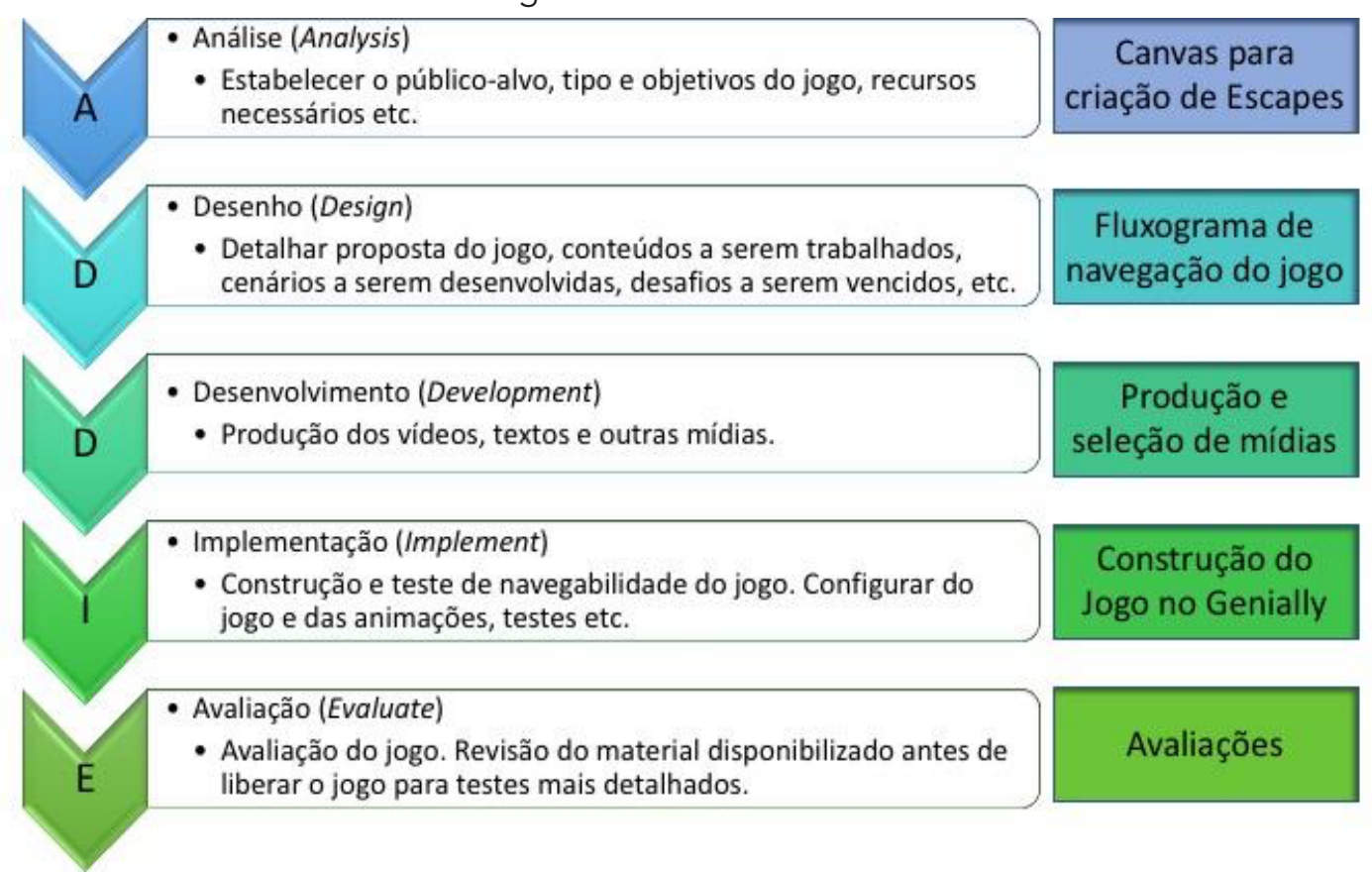

Fonte: Elaborada pelas autoras

O planejamento e desenvolvimento do Escape Room ocorreu durante um período de 3 semanas, que incluíram a escolha do aplicativo para ser utilizado no desenvolvimento do jogo, bem como a aprendizagem de como utilizá-lo. Após esta fase foi realizado o planejamento e o desenvolvimento da sala que envolveu, também a busca por imagens e sons que tivessem permissão de uso gratuito. Muitas das imagens utilizadas apresentam referências do local de onde foram obtidas.

O jogo foi desenvolvido no Genial.ly, versão Edu Pro. Este aplicativo foi escolhido por proporcionar agilidade e flexibilidade para a prototipação da aplicação, facilitando, assim, a implementação de mudança, além de disponibilizar para uso na construção do jogo modelos de Escape Room do tipo Breakout e várias imagens e sons gratuitos. Além destas vantagens ele permite a integração dos recursos criados nas várias plataformas existentes (Classroom, Teams, Moodle, Edmodo, Classdojo etc.) através de link ou incorporação.

\subsection{Características gerais}

No quadro 1 estão descritas as principais características do jogo.

Quadro 1 - Características gerais do jogo O Desafio das Metodologias Ativas

\begin{tabular}{|l|l|}
\hline \multicolumn{1}{|c|}{ Característica } & \multicolumn{1}{c|}{ Descrição } \\
\hline Público alvo & $\begin{array}{l}\text { Alunos do ensino técnico subsequente ou do ensino } \\
\text { superior de cursos da área de educação. }\end{array}$ \\
\hline Tipo & Escape Room, Educativo e Single Player \\
\hline Finalidade & Jogos didático. \\
\hline $\begin{array}{l}\text { Ferramenta de } \\
\text { desenvolvimento }\end{array}$ & $\begin{array}{l}\text { Software Genially (https://www.genial.ly/genially), versão } \\
\text { Edu Pro. }\end{array}$ \\
\hline $\begin{array}{l}\text { Requisitos de } \\
\text { software }\end{array}$ & Acesso via navegador de internet, online ou off-line \\
\hline Link para acesso & https://bit.ly/2TFzRss \\
\hline
\end{tabular}

Fonte: Elaborada pelas autoras 
Este jogo teve como principal objetivo educacional levar o jogador a demonstrar conhecimentos teóricos e práticos ao refletir sobre o uso de metodologias ativas de aprendizagem em contexto escolar.

O jogo, O Desafio das Metodologias Ativas, pode facilmente ser acessado de qualquer dispositivo que tenha acesso à Internet. Além disso, o assunto enfocado - metodologias ativas de aprendizagem em contexto escolar - tem gerado cada vez mais interesse dos profissionais da área de educação. Por ser este um jogo didático, foi especialmente concebido para o contexto educacional e totalmente explorado dentro dele. Por fim, outro ponto a ser observado é a falta de jogos que tratam de temas ligados à área da educação.

Os conteúdos tratados no jogo foram: Aprendizagem Centrada no Aluno, Metodologias Ativas de Aprendizagem, Aprendizagem Baseada em Problemas, Aprendizagem Baseada em Projetos e Instrução por Pares. Dentre os diversos temas relacionados às metodologias ativas de aprendizagem, estes temas foram escolhidos pois fazem parte do conteúdo programático do curso Técnico Subsequente em Multimeios Didáticos, curso para o qual o jogo foi projetado e no qual será testado.

\section{Estrutura do Jogo "O Desafio das Metodologias Ativas"}

Nesta seção, apresentaremos a estrutura do Jogo "O Desafio das Metodologias Ativas". Com base no modelo Canvas para Criação de Escapes Room, proposto pelo site Sistema Aberto para Escapes .

\subsection{Temática}

O jogo descrito neste artigo foi desenvolvido para apoiar a aprendizagem e a reflexão de estudantes de cursos da área de educação sobre conceitos básicos ligados ao tema Metodologias Ativas de Aprendizagem. O jogador tem como missão levar as metodologias ativas de aprendizagem para dentro da sala de aula, facilitando com isso a aprendizagem dos alunos. Para cumpri-la, ele deverá passar por quatro salas de aula diferentes e em cada uma delas realizar 2 desafios. Ao cumprir os dois desafios propostos em cada sala de aula, receberá um número que comporá a senha para completar a missão.
As Metodologias Ativas de Aprendizagem são métodos de ensino cujo foco é a aprendizagem centrada no estudante, que incitam a curiosidade, propõem desafios, engajam o aluno em vivências e propiciam a colaboração e a autonomia dos estudantes. Elas devem dar ênfase ao protagonismo do aluno, valorizando o envolvimento destes na construção de sua aprendizagem. Assim, quanto maior a proximidade entre as atividades escolares e as atividades da vida real, melhor (MORAN, 2013; MATTAR, 2017).

Dentre os vários métodos de ensino que apoiam as aprendizagens ativas, pode-se citar: Sala de Aula Invertida, a Instrução por Pares, o Método do Caso, a Aprendizagem Baseada em Problemas, a Aprendizagem Baseada em Projetos, Pesquisas, Design Thinking, e a Aprendizagem Baseada em jogos, que inspiraram a construção deste jogo. Ele tem como base trazer conceitos básicos sobre a aprendizagem centrada no estudante e metodologias ativas de aprendizagem, sendo que a aprendizagem baseada em problemas, a aprendizagem baseada em projetos e a instrução por pares foram escolhidas para comporem as 4 missões propostas neste jogo.

\subsection{Competências}

O jogo tem como objetivo levar os jogadores a refletirem sobre como levar a aprendizagem centrada nos estudantes para dentro da escola, com base no uso de metodologias ativas e, em especial, as principais diferenças existentes entre essas, bem como reconhecer as tarefas realizadas nas fases de pré-aula, aula e pósaula durante a execução do método Instrução por Pares.

Este jogo tem como foco, além do desenvolvimento de competências cognitivas promover 0 desenvolvimento de competências atitudinais. Trazendo para os alunos benefícios como a promoção no campo intelectual do desenvolvimento da lógica, memória, concentração, atenção, pensamento dedutivo, criatividade, imaginação, agilidade mental e, no campo emocional promover a expressão de emoções e o sentimento de realização.

\subsection{Conteúdos}


Os jogos utilizados na aprendizagem baseada em jogos devem ter resultados de aprendizagem definidos e, geralmente, projetados para equilibrar o assunto com o jogo e a capacidade do jogador de reter e aplicar o assunto ao mundo real (COJOCARIU; BOGHIAN, 2014). Os conteúdos neles tratados devem ser abordados sob várias perspectivas: método pedagógico, procedimento didático, organização da atividade de ensinoaprendizagem. Neste jogo foram abordados os conteúdos descritos no quadro 1.

Dentre os diversos temas relacionados às Metodologias Ativas de Aprendizagem existentes, esses conteúdos foram escolhidos pois fazem parte do conteúdo programático do curso Técnico Subsequente em Multimeios Didáticos, no qual o jogo será testado inicialmente.

\subsection{Recursos}

Com o objetivo de compartilhar conteúdos que serviram de base para a construção do conhecimento por parte dos alunos e para apoiar a resolução dos desafios propostos nas quatro missões, foram utilizados, como recursos didáticos: vídeos, animações e infográficos, conforme descrito no Quadro 2.

Quadro 2 - Lista do material de apoio à aprendizagem e conclusão dos desafios

\begin{tabular}{|l|l|l|}
\hline \multicolumn{1}{|c|}{ Conteúdo } & \multicolumn{1}{|c|}{ Fontes Utilizadas } & \multicolumn{1}{c|}{ Recursos Utilizadas } \\
\hline $\begin{array}{l}\text { Aprendizagem Centrada no } \\
\text { Estudante }\end{array}$ & $\begin{array}{l}\text { Meriguete, Passos e Jesus } \\
(2019)\end{array}$ & https://youtu.be/Qg6fLNQ9J0M \\
\hline $\begin{array}{l}\text { Metodologias Ativas de } \\
\text { Aprendizaqem }\end{array}$ & Moran (2013) e Mattar (2017) & https://youtu.be/6xLOBCJe4fs \\
\hline $\begin{array}{l}\text { Aprendizagem Baseada em } \\
\text { Problemas e Aprendizagem } \\
\text { Baseada em Projetos }\end{array}$ & (Barbosa, De Moura, 2013) & Infográfico \\
\hline Instrução por Pares & (Mattar, 2017) & https://youtu.be/iUEFD4rNCw4 \\
\hline
\end{tabular}

Fonte: Elaborada pelas autoras

Além do material listado no quadro 2, o jogo tem em todas as suas telas um ícone que ao ser clicado abre uma janela que contêm um vídeo com tradução para Libras dela, garantindo aos alunos com deficiência auditiva acesso igualitário ao jogo.

\subsection{Emergência}

Uma limitação de tempo para solucionar o enigma, tal como em qualquer projeto do mundo real, está comumente presente nos jogos do tipo Escape Room para introduzir um elemento de estresse, excitação e competição que podem ajudar o desenvolvimento de capacidades como a resiliência e concentração (LUI et al., 2020; MOURA, 2019). No caso do jogo aqui apresentado não há limite de tempo para que ele seja encerrado, mas há um contador de tempo para que o jogador possa saber o tempo que levou para completar o desafio final.

\subsection{Narrativa}

Os jogos do tipo Escape Room apresentam desafios a serem resolvidos para que os jogadores escapem de algum "lugar". Entretanto, o objetivo de um jogo do tipo Escape Room é mais do que simplesmente abrir portas e cadeados, ele busca oferecer aos jogadores uma experiência imersiva e um objetivo. Uma experiência imersiva é aquela que envolve o jogador em uma atividade cativante, de tal forma que tal envolvimento o faz perder a noção do tempo. Além disso, o tema do jogo deve estar presente em todo o jogo e funcionar em conjunto para criar uma experiência verossímil (WIEMKER; ELUMIR; CLARE, 2015). Por essas razões, a narrativa e os cenários são fatores importantes no projeto de criação do jogo.

○ jogo "O Desafio das Metodologias Ativas" traz como tema central uma escola, na qual o jogador precisa entrar obtendo a chave de entrada na escola. Ao 
entrar, o jogador será levado para o corredor central, a partir do qual poderá escolher missões que o levará a provocar mudanças na escola ao ajudar os professores a introduzirem $\mathrm{o}$ uso de metodologias ativas de aprendizagem em suas práticas docentes, facilitando com isso a aprendizagem dos alunos. Em cada uma das missões, o jogador será levado a uma sala de aula diferente na qual deverá resolver dois desafios que estão associados a um assunto descrito no início da missão. Ao resolver estes desafios, o jogador receberá um número que comporá a senha final, a qual terá de digitar em um painel digital para poder completar sua missão e ver do lado de fora da escola os alunos felizes com a sua aprendizagem (Figura 2).

Figura 2 - Telas de: descrição, início e fim do jogo
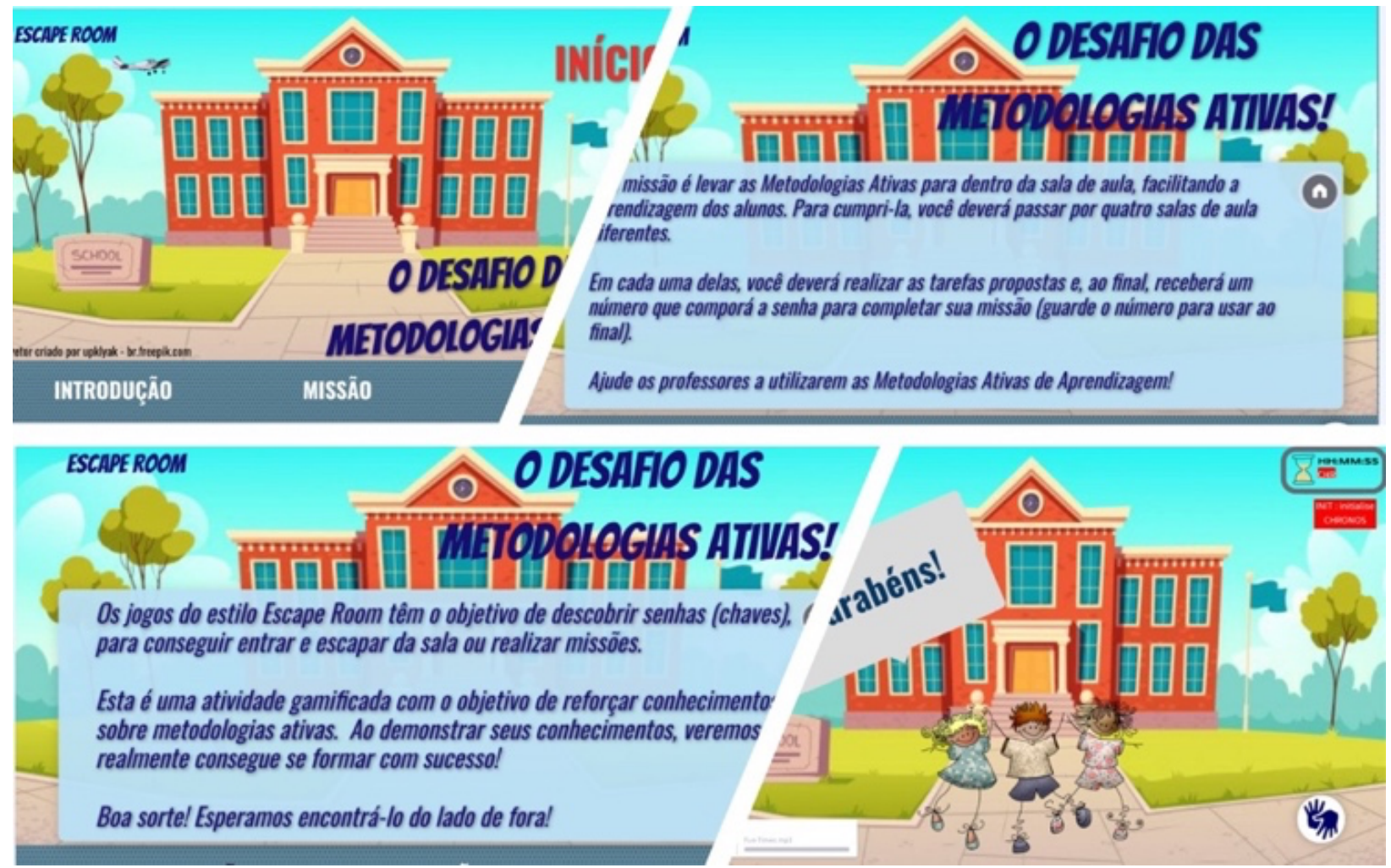

Fonte: Elaborada pelas autoras

\subsection{Cenário}

Este jogo terá como pano de fundo uma escola e trará como cenários: a entrada da escola (local onde o desafio terá início), o corredor central da escola e mais 4 salas de aula, nas quais será possível obter os 4 dígitos que lhe permite cumprir o segundo desafio do jogo, que é abrir uma fechadura digital que o levará para a parte externa da escola (Figura 3). 
Figura 3 - Cenários apresentados no Jogo

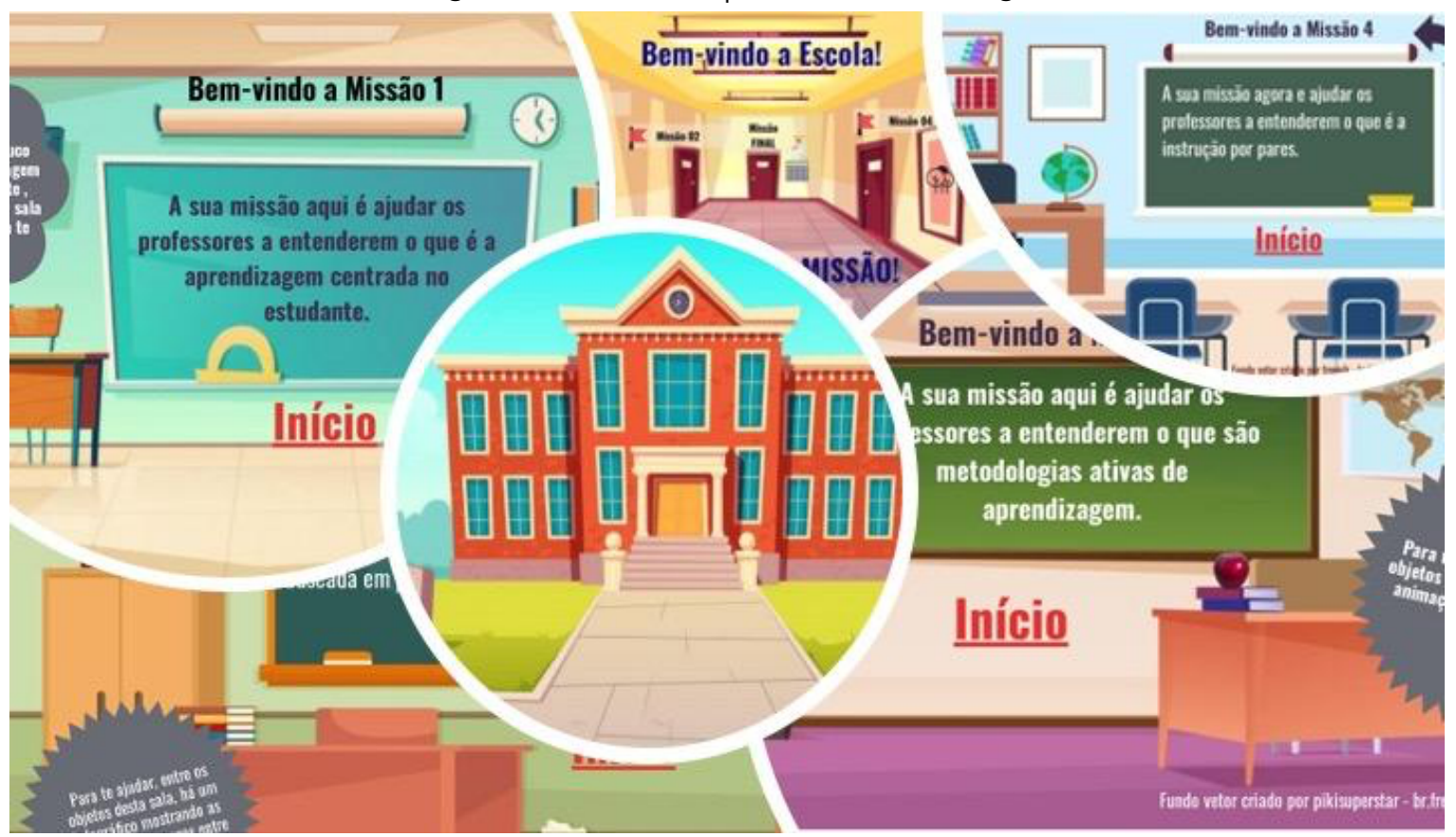

Fonte: Elaborada pelas autoras

\subsection{Desafio}

Para autores como Wiemker, Elumir e Clare (2015), os desafios nos jogos do tipo Escape Room devem estar conectados ao tema da sala e serem compreensíveis pelos jogadores com base nas informações disponíveis na sala. Este tipo de jogo pretende ser mais experiencial do que apenas uma série de quebra-cabeças. Em sua essência, os desafios dos ambientes de Escape Room usam um loop de jogo simples, que consiste em: um desafio a superar; uma solução (pode estar oculta) e uma recompensa por superar o desafio.

A criação dos desafios propostos pode ter três abordagens básicas: caminho linear; caminho aberto e caminho multilinear. Em um projeto linear, os desafios devem ser resolvidos em ordem; no projeto do caminho aberto, os desafios podem ser resolvidos em qualquer ordem, mas para sair da sala o jogador precisa vencer todos os desafios; já no caminho multilinear existe uma série de desafios de caminho linear que podem ser feitos em paralelo à escolha do jogador (JIMÉNEZ, 2020; WIEMKER; ELUMIR; CLARE, 2015).

No caso do jogo aqui descrito, temos dois desafios: entrar e sair da escola. O primeiro desafio é do tipo linear e o jogador precisa obter a chave da porta de entrada da escola respondendo a 3 perguntas iniciais sobre o seu curso (Técnico em Multimeios Didáticos). Ao obter sucesso nas respostas, o jogador receberá a chave que lhe permitirá abrir a porta e entrar no corredor da escola.

Já o segundo desafio é do tipo multilinear e o jogador, após entrar na escola, encontra-se em um corredor com 5 portas, que o levaram a quatro salas de aulas diferentes e a saída do prédio da escola. Ele deverá ajudar os professores a utilizarem as Metodologias Ativas de Aprendizagem e conseguir um código de 4 dígitos que lhe permitirá abrir uma fechadura digital que o levará para a parte externa da escola (Figura 4).

Para vencer os desafios propostos, o jogador deverá responder a questões a partir de pistas espalhadas pelos ambientes. Em cada uma das quatro salas ele deverá responder a 2 desafios e só ao vencê-los terá acesso a um dos 4 dígitos da senha final. Cada sala tratará de um tema específico, nelas além dos desafios há conteúdos teóricos que servirão de base para a solução dos desafios e para a construção de novos conhecimentos que poderão ser aplicados em contexto real. 
Figura 4 - Desafios, soluções e recompensas do jogo

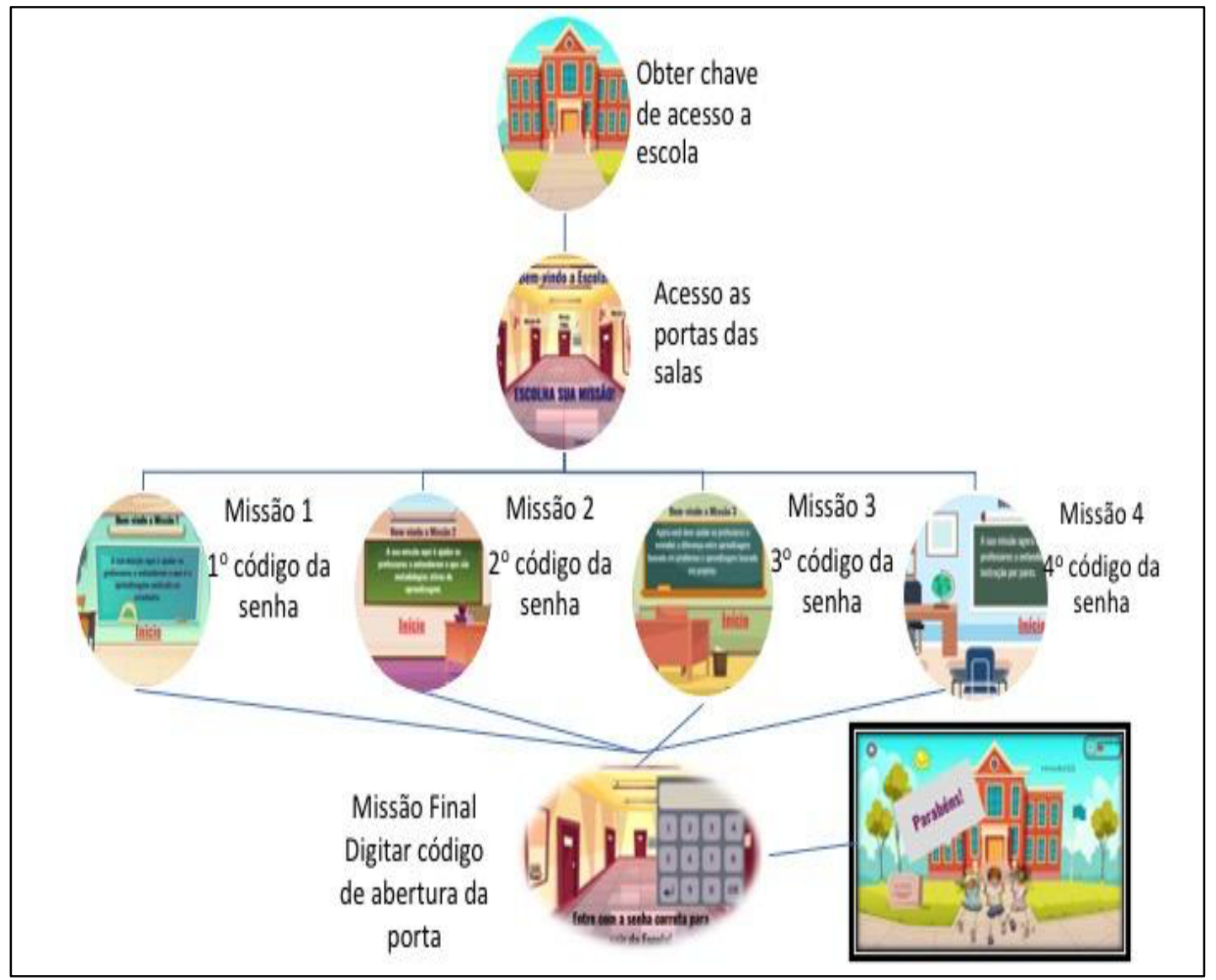

Fonte: Elaborada pelas autoras

\subsection{Feedback}

Em jogos de Escape Room físicos temos a figura do mestre do jogo, que supervisiona a sala e ajuda os jogadores se eles ficarem presos, sendo também responsável por apresentar o jogo aos jogadores e saudá-los quando eles ganham (WIEMKER; ELUMIR; CLARE, 2015).

No caso do jogo digital, este papel será realizado pelas telas de feedback que são apresentadas aos jogadores durante a partida. Esse sistema de feedback para $\circ$ jogador acontece através de telas de mensagens, que sinalizam quando este realizar uma tarefa de forma correta, informando-o de seu sucesso. Ao não conseguir realizar uma tarefa com sucesso, o jogador será incentivado a tentar novamente, sendo sempre redirecionado para o início do desafio do qual a tarefa faz parte. Além das telas de feedback, existem espalhados pelas salas de aula locais nos quais o jogador pode obter informações extras que o ajudarão a resolver os desafios propostos.

Figura 5 - Tipos de Feedbacks 

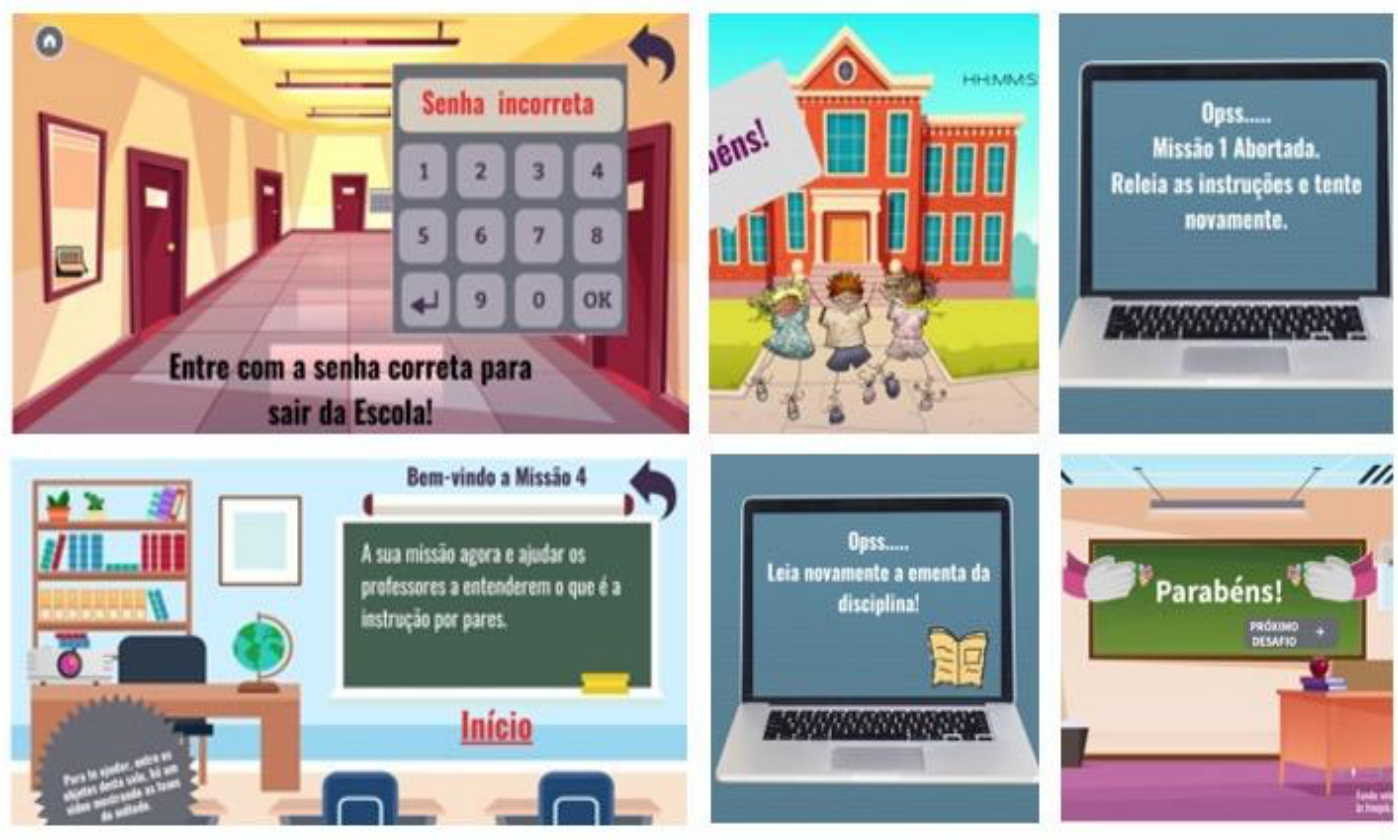

Fonte: Elaborada pelas autoras

\section{Avaliação e Resultados}

Inicialmente, o protótipo do jogo foi apresentado para um conjunto de especialistas para avaliação e, caso necessário, ajustes. Após a aprovação do protótipo do jogo por este conjunto de especialistas, a versão final do jogo foi avaliada por alunos de um curso Técnico Subsequente em Multimeios Didáticos, ofertado na modalidade a distância.

\subsection{Avaliação por Especialistas}

Para avaliar o protótipo do jogo foi utilizado como base o Modelo de Avaliação de Jogos Educacionais proposto por Savi et al. (2010). O modelo de questionário foi ajustado com base nos testes do coeficiente alfa de Cronbach, aplicado a cada um dos três constructos: motivação $(\mathbf{a}=0,924)$, experiência do usuário ( $\mathbf{a}=0,917)$, e conhecimento ( $\mathbf{a}=0,767)$, para garantir a sua confiabilidade. Cada item do constructo foi avaliado com base na escala Likert de 5 pontos ( $1=$ Discordo Totalmente; 2 = Discordo; 3 = Indiferente; 4 = Concordo; 5 = Concordo Totalmente) que permite oferecer um feedback mais granular e descobrir graus de opinião que podem fazer a diferença para entender o feedback recebido. Ele pode também indicar as áreas em que o jogo pode ser melhorado. O questionário foi criado no Google Forms, e a nota de cada item dos constructos foi calculada pela média das notas dadas pelos respondentes.

Responderam ao questionário 9 sujeitos, sendo 4 alunos de mestrado na área de ensino, 2 professores, 1 design educacional e 2 professores especialista em games. Os resultados do questionário podem ser vistos no Quadro 3. 


\begin{tabular}{|c|c|c|}
\hline \multicolumn{2}{|l|}{ Descritores } & Média \\
\hline \multicolumn{3}{|c|}{ Motivação } \\
\hline \multirow{2}{*}{ Atenção } & O design da interface do jogo é atraente. & 4,11 \\
\hline & Houve algo interessante no início do jogo que capturou minha atenção & 4,44 \\
\hline \multirow{4}{*}{ Relevância } & O conteúdo do jogo está relacionado com algo que eu já sabia. & 4,44 \\
\hline & Eu gostei tanto do jogo, que gostaria de aprender mais sobre o tema. & 4,00 \\
\hline & O conteúdo do jogo foi relevante para mim. & 4,67 \\
\hline & O conteúdo do jogo será útil para mim. & 4,33 \\
\hline \multirow{4}{*}{ Confiança } & O jogo foi fácil de ser entendido. & 3,89 \\
\hline & As informações me ajudaram a identificar e lembrar pontos importantes & 4,22 \\
\hline & O conteúdo é contextualizado e me ajudou a manter a atenção & 4,33 \\
\hline & Consegui entender uma boa parcela do material do jogo. & 4,11 \\
\hline \multirow{4}{*}{ Satisfação } & Completar o jogo me deu sentimento de realização. & 4,00 \\
\hline & Aprendi coisas que foram surpreendentes ou inesperadas & 3,67 \\
\hline & Textos de feedback e comentário ajudaram a me sentir recompensado. & 3,56 \\
\hline & Eu me senti bem ao completar o jogo. & 4,11 \\
\hline \multicolumn{3}{|c|}{ Experiência do Usuário } \\
\hline \multirow{4}{*}{ Imersão } & Não percebi o tempo passar enquanto jogava. & 3,44 \\
\hline & Perdi a consciência do que estava ao meu redor enquanto jogava. & 2,78 \\
\hline & Me senti mais no ambiente do jogo do que no mundo real. & 2,89 \\
\hline & Me senti estimulado a aprender com o jogo. & 4,11 \\
\hline \multirow{4}{*}{ Desafio } & Não me senti ansioso ou entediado. & 3,89 \\
\hline & Minhas habilidades melhoraram com a superação dos desafios. & 3,67 \\
\hline & O jogo oferece novos desafios num ritmo apropriado. & 3,78 \\
\hline & O jogo é desafiador, as tarefas não são muito fáceis nem muito difíceis. & 3,67 \\
\hline \multirow{3}{*}{ Confiança } & Me senti bem-sucedido. & 4,22 \\
\hline & Me senti competente. & 4,11 \\
\hline & Senti que estava tendo progresso durante o jogo. & 4,11 \\
\hline \multirow{3}{*}{ Interação Social } & Senti que estava colaborando com outros colegas. & 2,44 \\
\hline & A colaboração no jogo ajuda a aprendizagem. & 3,67 \\
\hline & O jogo suporta a interação social entre os jogadores. & 2,56 \\
\hline \multirow{4}{*}{ Divertimento } & Gostei de utilizar este jogo por bastante tempo. & 2,89 \\
\hline & Jogaria este jogo novamente. & 3,67 \\
\hline & Fiquei torcendo para o jogo não acabar logo. & 3,78 \\
\hline & Achei o jogo movimentado. & 3,44 \\
\hline
\end{tabular}




\begin{tabular}{|c|c|c|}
\hline \multicolumn{2}{|l|}{ Descritores } & Média \\
\hline \multicolumn{3}{|c|}{ Conhecimento } \\
\hline \multirow{4}{*}{ Aprendizagem } & Após o jogo consigo lembrar de mais informações relacionadas ao tema. & 4,22 \\
\hline & Após o jogo consigo compreender melhor o tema apresentado. & 4,00 \\
\hline & Após o jogo sinto que consigo aplicar melhor os conteúdos. & 3,67 \\
\hline & Os conteúdos foram abordados de forma a facilitar o meu aprendizado. & 4,22 \\
\hline
\end{tabular}

Fonte: Elaborada pelas autoras

Como é possível ver no Quadro 3, o protótipo do jogo obteve uma excelente avaliação em relação aos quesitos Motivação, Experiência do Usuário e Conhecimentos. $\bigcirc$ único descritor que não foi bem avaliado foi o da interação social, o que já era esperado uma vez que o jogo não foi planejado para ser jogado de forma colaborativa e não existe, nesta versão, a possibilidade de interação com outros jogadores. Contudo, nada impede que o professor possa incentivar os alunos a se juntarem em grupo para jogarem, e dessa forma promova a socialização e a interação entre eles. Portanto, o protótipo do jogo tornou-se a versão final, sem atualizações.

\subsection{Avaliação por alunos de um curso Técnico} Subsequente em Multimeios Didáticos, ofertado na modalidade a distância

O jogo, após aprovação pelos especialistas, foi avaliado por alunos de um curso Técnico Subsequente em Multimeios Didáticos, ofertado na modalidade a distância.

Disponibilizamos, para estes alunos, uma pesquisa de cunho quantitativo, no intuito de avaliar os itens pedagógicos do jogo, a motivação e a experiência dos usuários e identificar possíveis melhorias. Responderam a pesquisa 16 alunos. Dos respondentes, 87,5\% são do sexo feminino, 68,8\% estão na faixa etária de 26 a 45 anos e 68,8\% possuem Graduação ou Mestrado.

Com relação à Motivação, no quesito Atenção, podemos observar os resultados na Figura 6. Em relação à afirmação "O design da interface do jogo é atraente", 7 responderam "Concordo Totalmente" e 9 responderam "Concordo". Em relação à afirmação "Houve algo interessante no início do jogo que capturou minha atenção", 8 alunos responderam "Concordo Totalmente", 7 "Concordo" e apenas 1 respondeu "Discordo".

Figura 6 - Avaliação do quesito Atenção

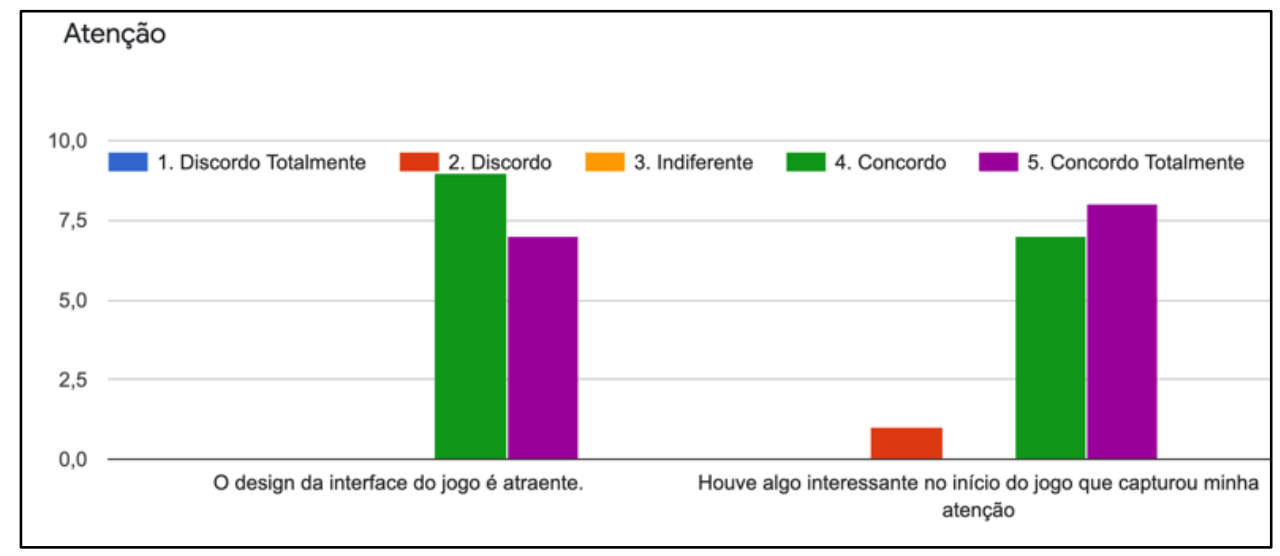

Fonte: Elaborada pelas autoras 
Com relação à Motivação, no quesito Relevância, podemos observar os resultados na Figura 7. Em relação à afirmação "O conteúdo do jogo está relacionado com algo que eu já sabia", 10 alunos responderam "Concordo Totalmente", 5 "Concordo" e 1 "Indiferente". Em relação à afirmação "Eu gostei tanto do jogo, que gostaria de aprender mais sobre o tema", 7 alunos responderam "Concordo Totalmente", 8
"Concordo" e 1 "Indiferente". Em relação à afirmação "O conteúdo do jogo foi relevante para mim", 11 alunos responderam "Concordo Totalmente" e 5 "Concordo". Por fim, em relação à afirmação "O conteúdo do jogo será útil para mim", 9 alunos responderam "Concordo Totalmente" e 7 "Concordo".

Figura 7 - Avaliação do quesito Relevância

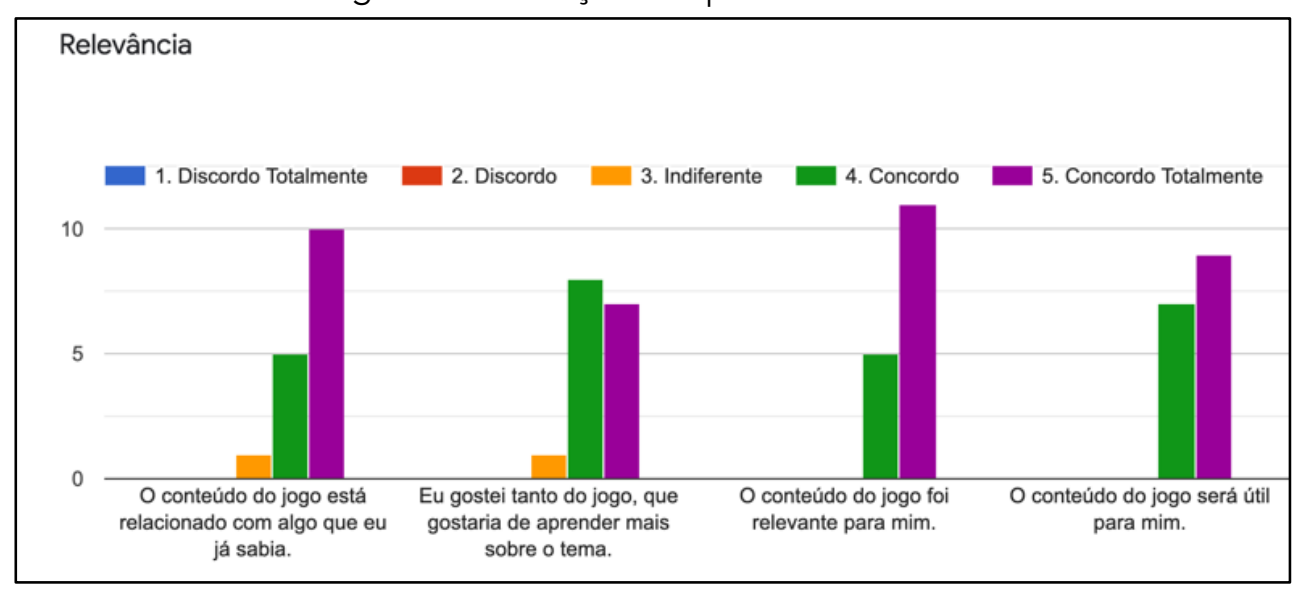

Fonte: Elaborada pelas autoras

Com relação à Motivação, no quesito Confiança, podemos observar os resultados na Figura 8 . Em relação à afirmação "O jogo foi fácil de ser entendido", 6 alunos responderam "Concordo Totalmente", 6 "Concordo", 3 "Indiferente" e 1 "Discordo Totalmente". Em relação à afirmação "As informações me ajudaram a identificar e lembrar importantes", 12 alunos responderam "Concordo Totalmente" e 4 "Concordo". Em relação à afirmação "O conteúdo é contextualizado e me ajudou a manter a atenção", 11 alunos responderam "Concordo Totalmente" e 5 "Concordo". Por fim, em relação à afirmação "Consegui entender uma boa parcela do material do jogo", 9 alunos responderam "Concordo Totalmente", 6 "Concordo" e 1 "Indiferente". 
Figura 8 - Avaliação do quesito Confiança

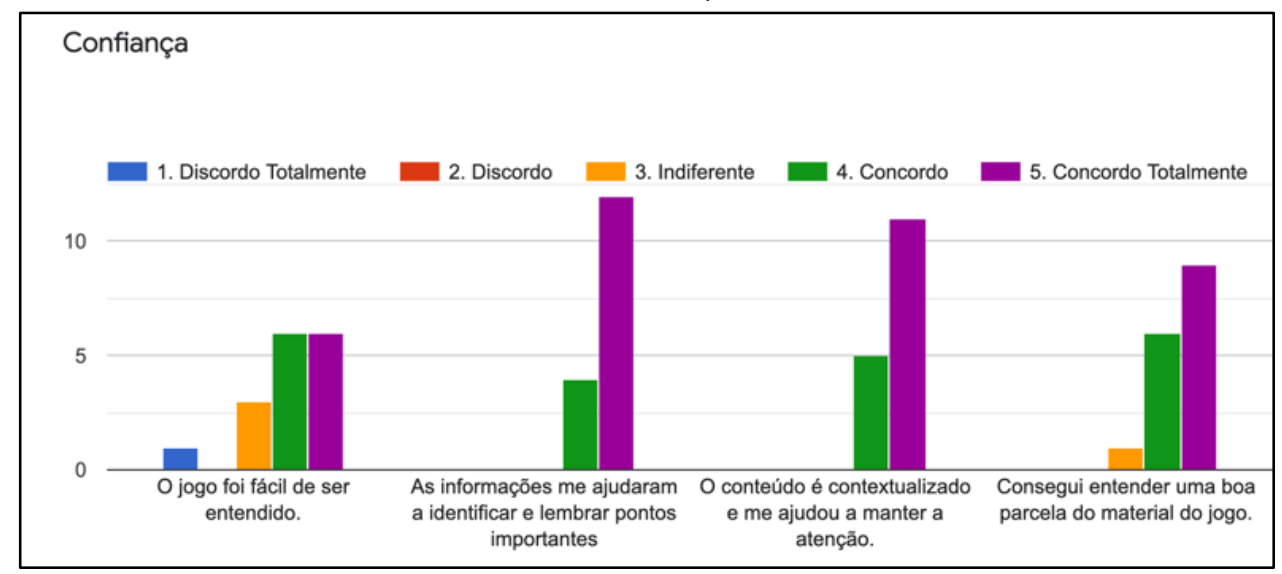

Fonte: Elaborada pelas autoras

Com relação à Motivação, no quesito Satisfação, podemos observar os resultados na Figura 9. Em relação à afirmação "Completar o jogo me deu sentimento de realização", 11 alunos responderam "Concordo Totalmente", 4 "Concordo" e 1 "Indiferente". Em relação à afirmação "Aprendi coisas no jogo que foram surpreendentes ou inesperadas", 8 alunos responderam "Concordo Totalmente", 5 "Concordo" e 3
"Indiferente". Em relação à afirmação "Textos de feedback e comentários ajudaram a me sentir recompensado", 6 alunos responderam "Concordo Totalmente", 7 "Concordo" e 3 "Indiferente". Por fim, em relação à afirmação "Eu me senti bem ao completar o jogo", 10 alunos responderam "Concordo Totalmente" e 6 "Concordo".

Figura 9 - Avaliação do quesito Satisfação

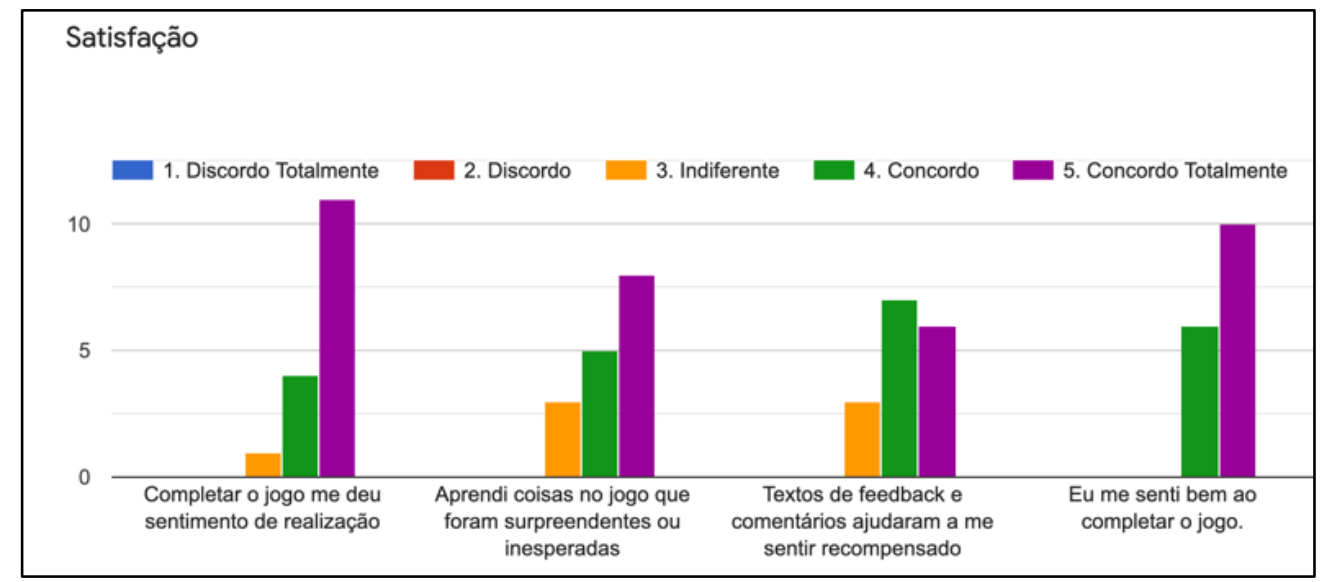

Fonte: Elaborada pelas autoras

Com relação à Experiência do usuário, no quesito Imersão, podemos observar os resultados na Figura 10. Em relação à afirmação "Não percebi o tempo passar enquanto jogava", 7 alunos responderam "Concordo Totalmente", 4 "Concordo", 4 "Indiferente" e 1 "Discordo". Em relação à afirmação "Perdi a consciência do que estava ao meu redor enquanto jogava", 7 alunos responderam "Concordo Totalmente", 3 "Concordo", 2 "Indiferente", 2 "Discordo" e 2 "Discordo Totalmente". Em relação à afirmação "Me senti mais no ambiente do jogo do que no mundo real", 5 alunos responderam "Concordo Totalmente", 8 "Concordo", 1 "Indiferente" e 2 "Discordo". 
Por fim, em relação à afirmação "Me senti estimulado a aprender com o jogo", 7 alunos responderam "Concordo Totalmente" e 9 "Concordo".

Figura 10 - Avaliação do quesito Imersão

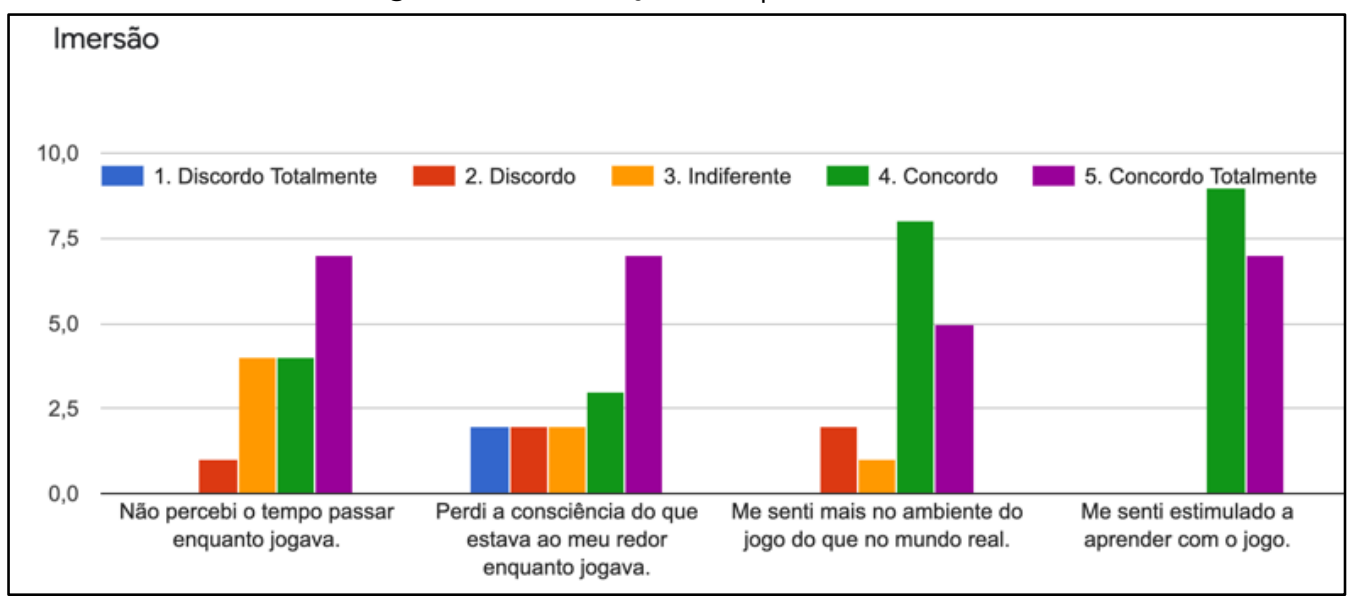

Fonte: Elaborada pelas autoras

Com relação à Experiência do usuário, no quesito Desafio, podemos observar os resultados na Figura 11. Em relação à afirmação "Não me senti ansioso ou entediado", 8 alunos responderam "Concordo Totalmente", 3 "Concordo", 3 "Indiferente" e 2 "Discordo". Em relação à afirmação "Minhas habilidades melhoraram com a superação dos desafios", 7 alunos responderam "Concordo Totalmente", 7 "Concordo", 1
"Indiferente" e 1 "Discordo". Em relação à afirmação "O jogo oferece novos desafios num ritmo apropriado", 5 alunos responderam "Concordo Totalmente", 10 "Concordo" e 1 "Discordo". Por fim, em relação à afirmação "O jogo é desafiador, as tarefas não são muito fáceis nem muito difíceis", 7 alunos responderam "Concordo Totalmente", 8 "Concordo" e 1 "Indiferente".

Figura 11 - Avaliação do quesito Desafio

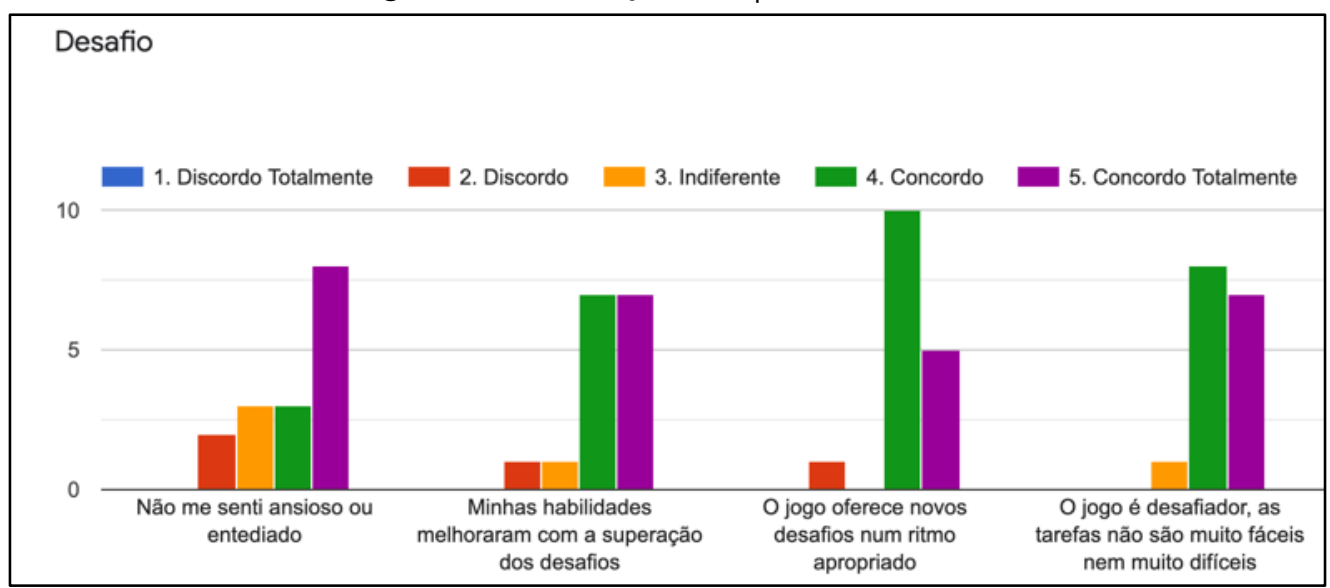

Fonte: Elaborada pelas autoras

Com relação à Experiência do usuário, no quesito Confiança, podemos observar os resultados na Figura 12. Em relação à afirmação "Me senti bem-sucedido", 7 alunos responderam "Concordo Totalmente", 6 "Concordo", 2 "Indiferente" e 1 "Discordo Totalmente". Em relação à afirmação "Me senti competente" , 6 alunos 
responderam "Concordo Totalmente" , 7 "Concordo", 2 "Indiferente" e 1 "Discordo Totalmente". Por fim, em relação à afirmação "Senti que estava tendo progresso durante o desenrolar do jogo", 7 alunos responderam "Concordo Totalmente", 8 "Concordo" e 1 "Discordo".

Figura 12 - Avaliação do quesito Confiança

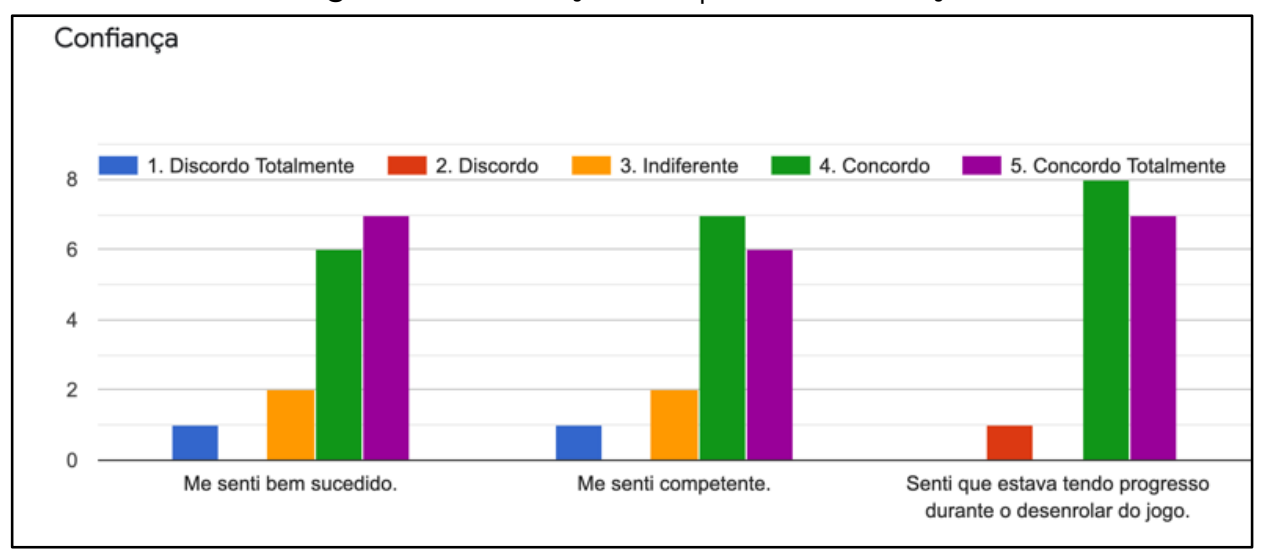

Fonte: Elaborada pelas autoras

Com relação à Experiência do usuário, no quesito Interação Social, podemos observar os resultados na Figura 13. Em relação à afirmação "Senti que estava colaborando com outros colegas", 2 alunos responderam "Concordo Totalmente", 4 "Concordo", 6 "Indiferente", 2 "Discordo" e 2 "Discordo Totalmente". Em relação à afirmação "A colaboração no jogo ajuda a aprendizagem", 4 alunos responderam "Concordo Totalmente", 8 "Concordo", 3 "Indiferente" e 1 "Discordo Totalmente". Por fim, em relação à afirmação "O jogo suporta a interação social entre os jogadores", 1 aluno respondeu "Concordo Totalmente", 5 "Concordo", 5 "Indiferente", 1 "Discordo" e 4 "Discordo Totalmente".

Figura 13 - Avaliação do quesito Interação Social

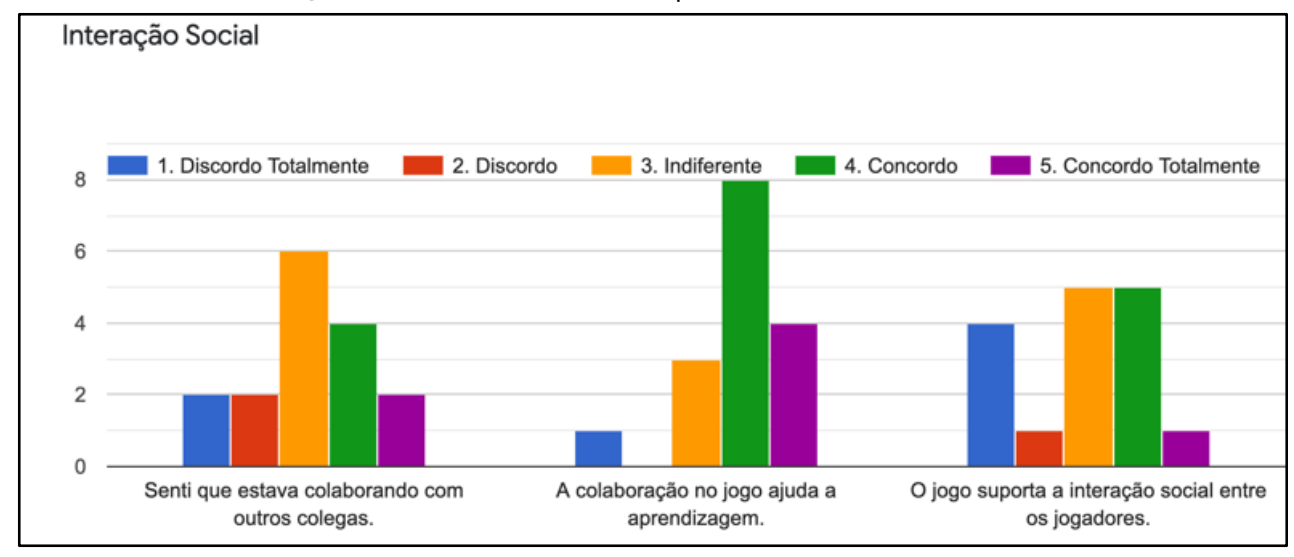

Fonte: Elaborada pelas autoras

Com relação à Experiência do usuário, no quesito Divertimento, podemos observar os resultados na Figura 14. Em relação à afirmação "Gostei de utilizar este jogo por bastante tempo", 9 alunos responderam "Concordo Totalmente", 5 "Concordo" e 2 "Indiferente". Em relação à afirmação "Jogaria este jogo novamente", 9 alunos responderam "Concordo Totalmente" e 7 "Concordo". Em relação à afirmação "Fiquei torcendo para o jogo não acabar logo", 5 alunos responderam "Concordo Totalmente", 4 "Concordo", 6 "Indiferente" 
e 1 "Discordo". Por fim, em relação à afirmação "Achei o jogo movimentado", 7 alunos responderam
"Concordo Totalmente", 7 "Concordo", 1 "Indiferente" e 1 "Discordo".

Figura 14 - Avaliação do quesito Divertimento

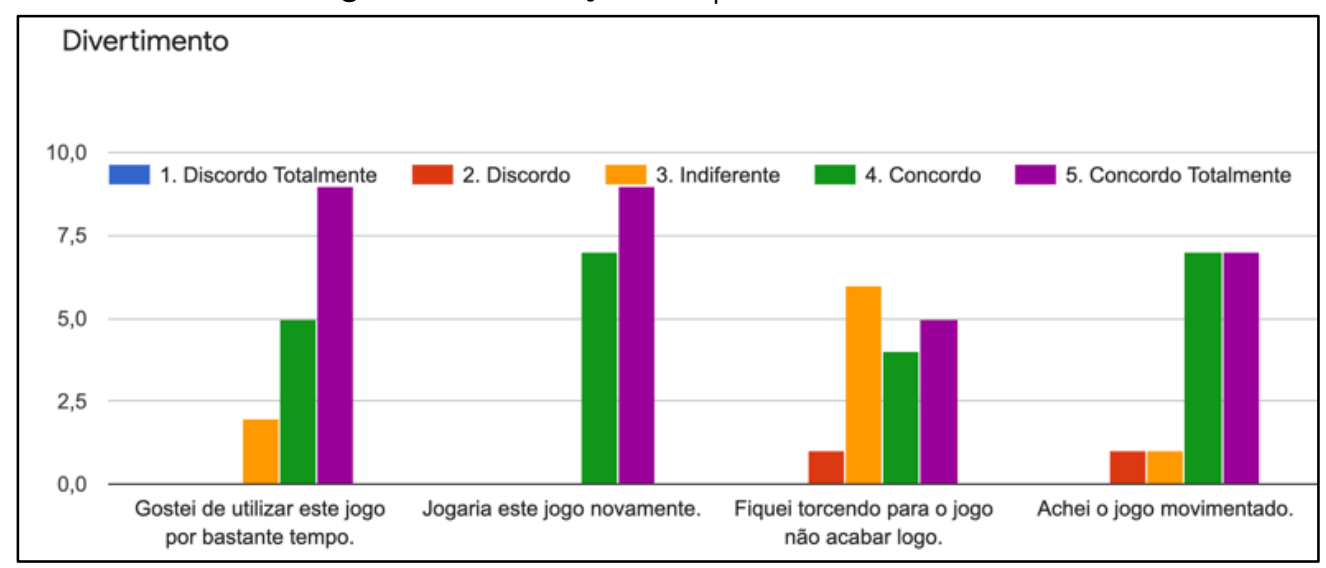

Fonte: Elaborada pelas autoras

Com relação ao Conhecimento, no quesito Aprendizagem, podemos observar os resultados na Figura 15. Em relação à afirmação "Após o jogo consigo lembrar de mais informações relacionadas ao tema", 9 alunos responderam "Concordo Totalmente", 6 "Concordo" e 1 "Indiferente". Em relação à afirmação "Após o jogo consigo compreender melhor os temas apresentados no jogo", 9 alunos responderam
"Concordo Totalmente", 6 "Concordo" e 1 "Indiferente". Em relação à afirmação "Após o jogo sinto que consigo aplicar melhor os conteúdos", 7 alunos responderam "Concordo Totalmente", 7 "Concordo" e 2 "Indiferente". Por fim, em relação à afirmação "Os conteúdos foram abordados de forma a facilitar o meu aprendizado", 11 alunos responderam "Concordo Totalmente" e 5 "Concordo".

Figura 15 - Avaliação do quesito Aprendizagem

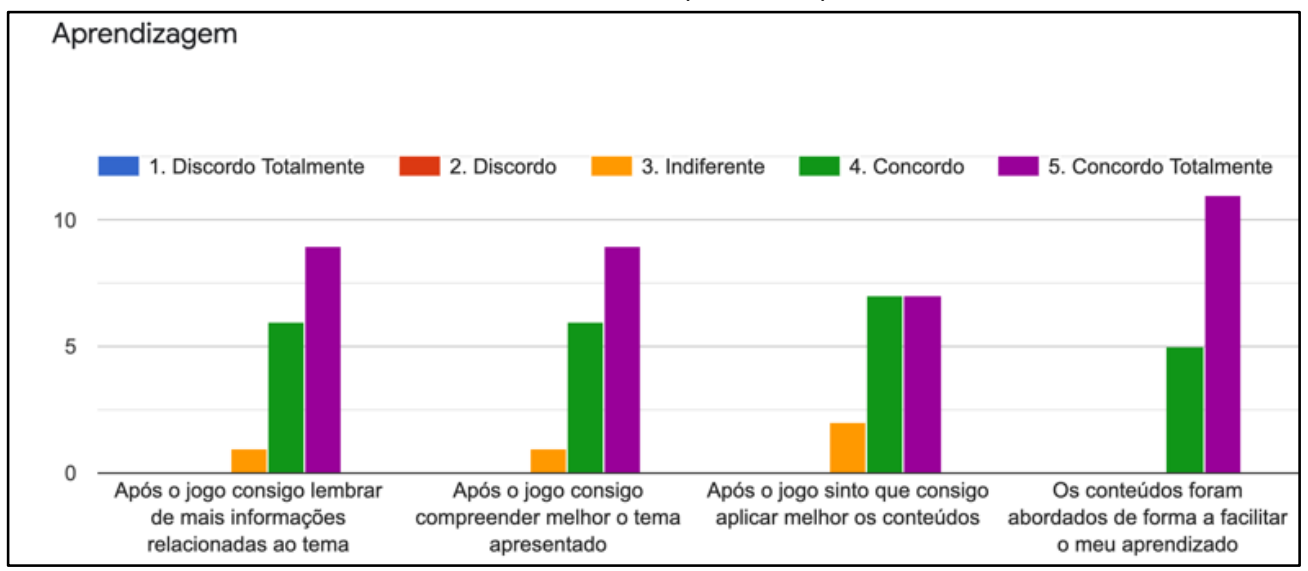

Fonte: Elaborada pelas autoras

Ao serem questionados "Em uma escala de 0 a 10, que nota você atribui ao jogo?", 7 alunos responderam
10, 6 responderam 9, 2 responderam 8 e apenas 1 respondeu 6, conforme Figura 16. 
Figura 16 - Nota do Jogo

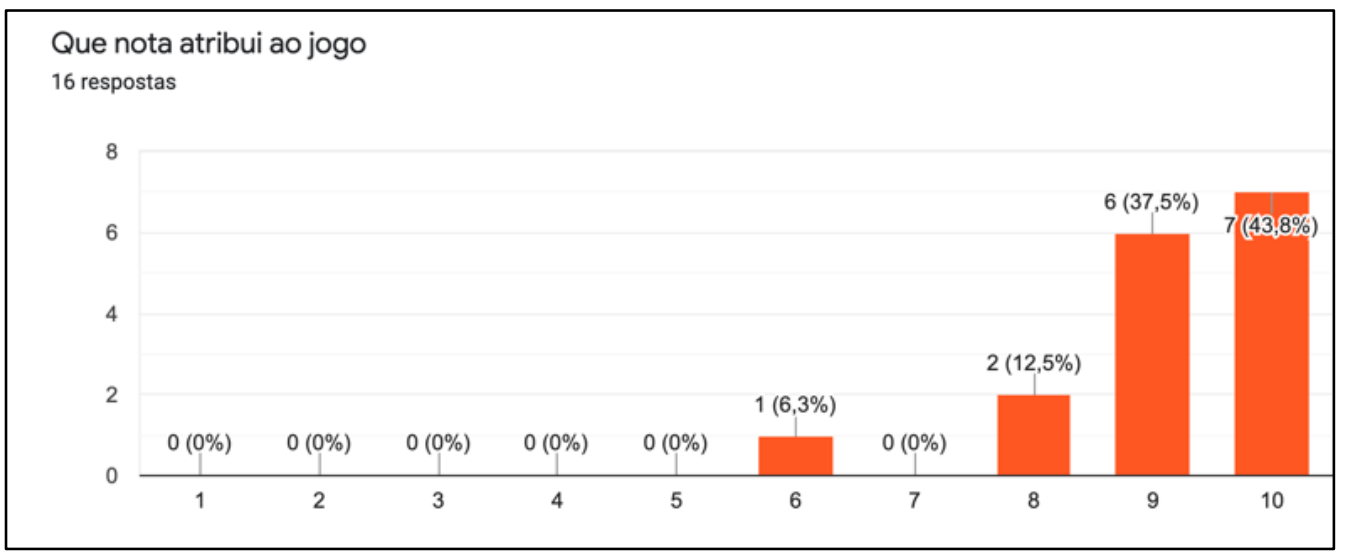

Fonte: Elaborada pelas autoras

Por fim, as respostas abertas dos alunos sobre se gostariam de deixar algum comentário, destacamos algumas:

"Não conhecia essa modalidade de jogo, e achei de fácil compreensão e também para jogar. Muito divertido e gostaria de conhecer mais sobre."

"Divertido e segura a atenção"

"Bom jogo e de fácil entendimento."

"gostei muito do layout, achei bem divertido o jogo"

\section{Conclusões}

Este trabalho apresenta um jogo educativo digital do tipo Escape Room, que foi desenvolvido para apoiar a disciplina de Metodologias Ativas de um curso Técnico Subsequente em Multimeios Didáticos ofertado na modalidade a distância. O jogo foi desenvolvido no aplicativo Genially e está disponível para acesso na Internet.

Este jogo foi avaliado inicialmente por um grupo de 6 usuários, que o analisou sob o ponto de vista do aluno, do professor e do design educacional. Em seguida, foi avaliado junto aos alunos do curso técnico, inclusive por alunos surdos para o qual ele foi projetado.

Quanto às teorias de aprendizagem, relacionadas ao uso de Escape Room na educação, descritas neste trabalho, acredita-se que a que mais se destaca neste jogo é o construtivismo, uma vez que o jogo procura levar o aluno a interpretar novas informações com base em um contexto real e a partir de seus conhecimentos prévios construir novos conhecimentos.

Este jogo possui um grande potencial enquanto instrumento educacional, uma vez que existem poucos jogos educativos no mercado que tenham como base conteúdos pedagógicos, sendo que um outro grande diferencial é a sua acessibilidade, uma vez que está todo traduzido para a Língua Brasileira de Sinais - Libras.

\section{Referências}

ABDUL JABBAR, Azita lliya; FELICIA, Patrick. Gameplay engagement and learning in game-based learning: $A$ systematic review. Review of educational research, v. 85, n. 4, p. 740-779, 2015.

ABT, Clark C. Serious game. Lanham: University Press of America, 1987, p. 13.

BARBOSA, Eduardo Fernandes; DE MOURA, Dácio Guimarães. Metodologias ativas de aprendizagem na educação profissional e tecnológica. Boletim Técnico do Senac, v. 39, n. 2, p. 48-67, 2013.

COJOCARIU, Venera-Mihaela; BOGHIAN, loana. Teaching the relevance of game-based learning to preschool and primary teachers. Procedia-Social and Behavioral Sciences, v. 142, p. 640-646, 2014. 
DE MACEDO, Lino; PETTY, Ana Lúcia Sícoli; PASSOS, Norimar Christe. Os jogos e o lúdico na aprendizagem escolar. Artmed Editora, 2009.

HUIZINGA, Johan. Homo ludens: o jogo como elemento da cultura. São Paulo: Perspectiva. 8 ed. 2017.

JIMÉNEZ, Cristina et al. Digital Escape Room, Using Genial. Ly and A Breakout to Learn Algebra at Secondary Education Level in Spain. Education Sciences, v. 10, n. 10, p. 271, 2020.

LIU, Chantal et al. Feasibility of a paediatric radiology Escape Room for undergraduate education. Insights into imaging, v. 11, n. 1, p. 1-11, 2020.

MATTAR J. Metodologias Ativas: para a educação presencial, blended e a distância. São Paulo: Artesanato Educacional, 2017.

MATTAR, João. Games em educação: como os nativos digitais aprendem. São Paulo: Pearson Prentice Hall, 2010.

MERIGUETE, M. S. P.; PASSOS, M. L. S.; JESUS, R. G. Formação, ação e reflexão: um curso sobre o uso de metodologias ativas para professores da Educação Profissional e Tecnológica. Vitória: Instituto Federal de Educação, Ciência e Tecnologia do Espírito Santo, 2019, v. 1. p. 95. e-Book PDF.

MORAN, J. M. Mudando a educação com metodologias ativas. In: SOUZA, C. A.; MORALES, O. E. T. (orgs). Convergências Midiáticas, Educação e cidadania: aproximações jovens. Coleção Mídias Contemporâneas, 2015.

MOURA, Adelina, Escape Room Educativo: os alunos como produtores criativos. In: GILT - Games, Interaction and Learning Technologies. 2019.

OUARIACHI, Tania; WIM, Elving JL. Escape Rooms as tools for climate change education: an exploration of initiatives. Environmental Education Research, p. 1-14, 2020.

PRENSKY, Marc. Digital Game-Based Learning. Paragon House. Edição do Kindle. 2013.
SAVI, Rafael et al. Proposta de um modelo de avaliação de jogos educacionais. RENOTE-Revista Novas Tecnologias na Educação, v. 8, n. 3, 2010.

WHITTON, Nicola. Playful learning: tools, techniques, and tactics. Research in Learning Technology, v. 26, 2018.

WIEMKER, Markus; ELUMIR, Errol; CLARE, Adam. Escape Room games. Game Based Learning, v. 55, 2015.

ZHANG, X.; LEE, H.; RODRIGUEZ, C.; RUDNER, J.; CHAN, T. M.; e PAPANAGNOU, D. Trapped as a group, escape as a team: applying gamification to incorporate team-building skills through an 'escape room' experience. Cureus, v. 10, n. 3, p. 1-9, 2018. 